\title{
PRESENT STATUS OF THE BLACK-TAILED PRAIRIE DOG IN SASKATCHEWAN
}

\author{
by Larry Kerwin, 2044 Francis Street, Regina, and
}

\section{Cam G. Scheelhaase, Department of Natural Resources, Regina}

The black-tailed prairie dog (Cynomys ludovicianus ludovicianus) occurs nowhere in Canada except in one small part of Saskatchewan. Although conservationists are concerned about the survival of this species (Novakowski, 1970 ), the status of the prairie dog population in this province has not been thoroughly studied. The most recent survey was made in 1962 when their population was estimated to be 45,000 animals inhabiting some 2,400 acres (Paynter, 1962).

During the summer of 1970 , the Val Marie area was the location of sage grouse and pronghorn investigations and during this period, 16 prairie dog colonies or towns were located. The colonies varied in size from 300 acres to less than one acre. All but one of the colonies were active. The distribution of these colonies is shown in Figure 1. The location and calculated size of each colony, and the estimated number of burrows in each are shown in Table 1.

The number of burrows in each town was estimated according to the formula established by Koford (1958) on the basis of his findings during a survey made in Nebraska. Koford established an average number of 20 burrows per acre. On the basis of a random sample of four separate towns in Saskatchewan we concluded that this figure was generally valid.

While the number of burrows present is a function of the number of animals in the colony, it is not a good index because it reflects past as well as present conditions. According to Koford, the number of burrows in an area indicates the maximum concentration of prairie dogs during the season of highest precipitation, from April to September, for most holes are started then. Consequently, we did not estimate the number of dogs in a colony by the number of burrows. To obtain a more accurate census of the population, Koford suggests counting the animals an hour or two after sunrise or before sunset, but we were unable to carry out such a count this year for various reasons. We therefore used an average density figure established by King (1955) during a three-year study in South Dakota. Although King's data was established in South Dakota, it was nevertheless felt that it gave a useful estimate of the present Saskatchewan population of prairie dogs.

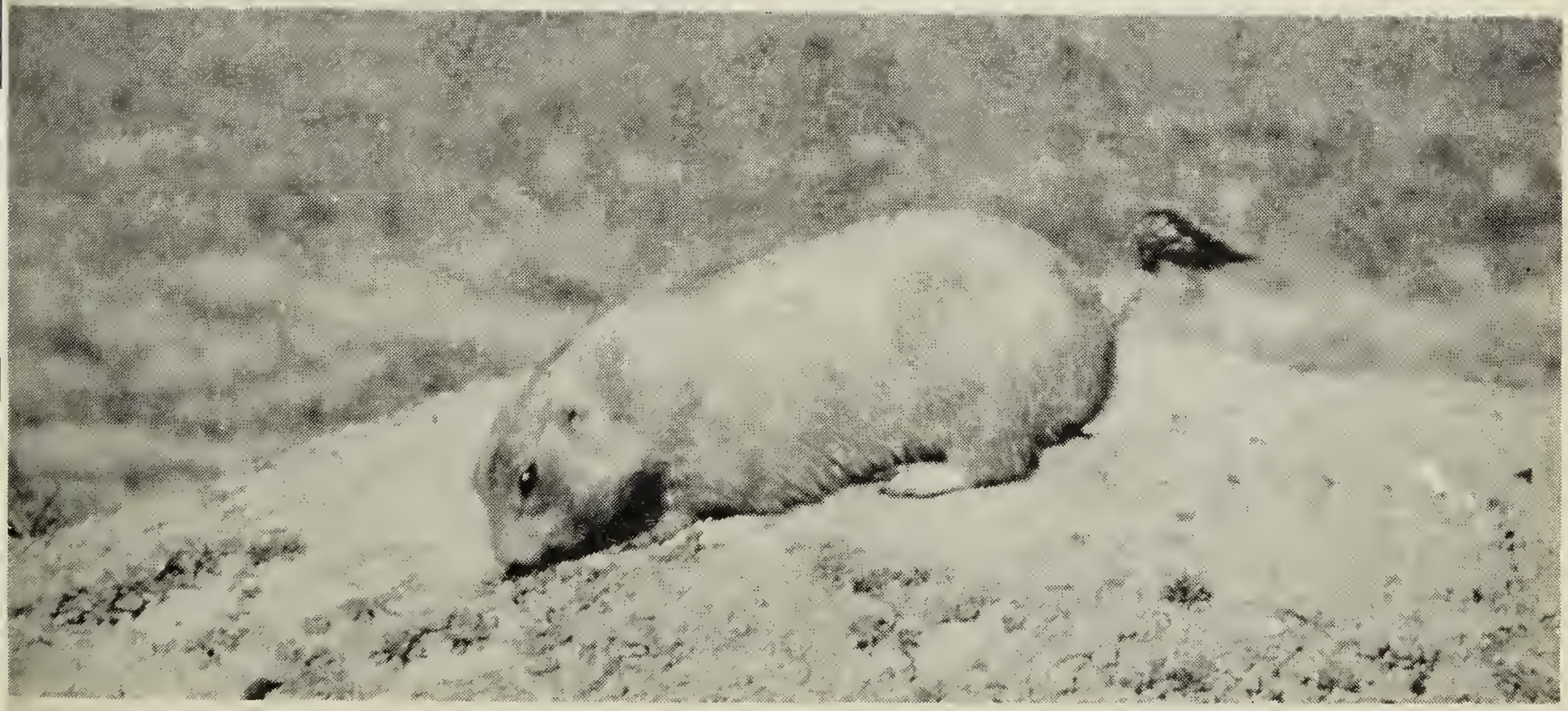

Black-tailed Prairie Dog

Photo by Fred W. Lahrman 


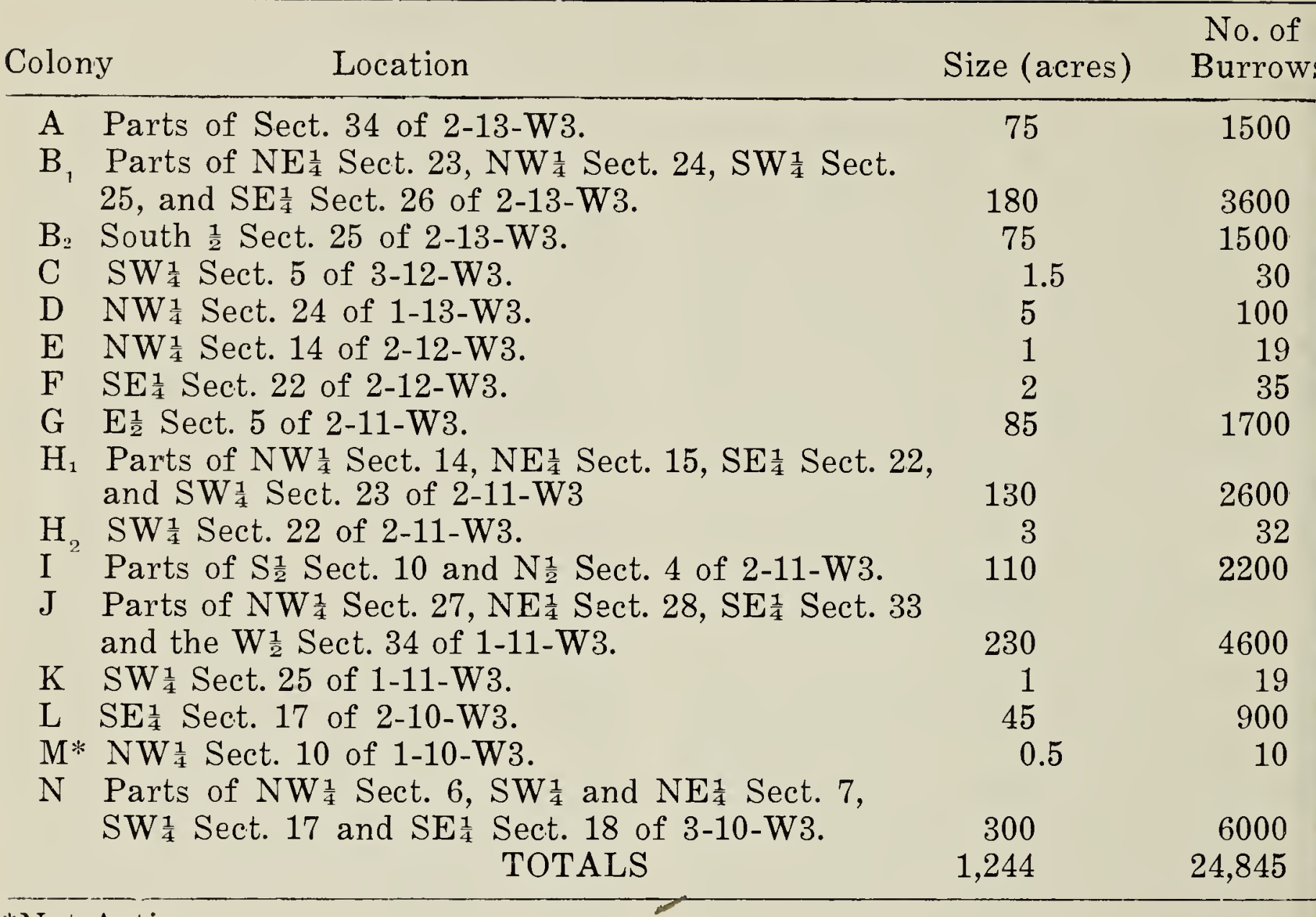

*Not Active.

During the summer, we found and examined a total of 16 colonies. In the 16 colonies censused, we estimated a total of 24,845 burrows occupying a total area of about 1,244 acres. On the basis of this information, and estimating an average density of 8.7 animals per acre, the total population was estimated to be 10,823 animals. Even if calculated on the basis of 15.0 animals per acre, which King reported to be a maximum population a'ensity for the species in his South Dakota study, the total estimated population would be only 18,660 . Both these figures are well below Paynter's estimate of 45,000 animals.

The 16 colonies that were found in the summer of 1970 may not represent all the colonies present in the area. However, the figure represents an increase in the number of colonies that have been previously reported. Paynter (1962) reports eight colonies. Beck (1958) reports that there are eleven or more distinct colonies. Novakowski (1970) makes reference to "a few live colonies."
A number of factors, of course, are influential in creating fluctuations in the prairie dog population. In part, changes are due to poisoning carried out by the ranchers to protect their grazing lands. If poisoning is not carried out continuously in a colony, however, there are usually enough animals left to keep the colony alive. One example of this is the colony shown on the map as Colony $J$, which was thought to have been poisoned out in 1962 (see The Blue Jay, 20:125) and has not been subject to further control. It now has more animals than in 1962 and is still growing.

But even without the influence of man, the number of animals in a population fluctuates widely. Sometimes the population of a dog town dwindles or disappears in the absence of an obvious cause such as drought, flood, disease, or predation (Koford, 1958). Thus there is always the possibility that a combination of such factors could wipe out any or all of the dog towns present in this province.

At present, only one colony is afford- 
